Int. J. Electrochem. Sci., 11 (2016) 9959 - 9971

\title{
Biosynthesis of Silver Nanoparticles using Mimosa Pudica Plant root extract: Characterization, Antibacterial Activity and Electrochemical Detection of Dopamine
}

\author{
V. Sreenivasulu ${ }^{1}$, N. Siva Kumar, ${ }^{2, *}$, M. Suguna ${ }^{3}$, M. Asif $^{2, *}$, Ebrahim H. Al-Ghurabi ${ }^{2}, Z . X$. Huang $^{1}, Z$. \\ Zhen ${ }^{1}$ \\ ${ }^{1}$ Institute of Atmospheric Environmental Safety and Pollution Control, Jinan University, Huangpu \\ Road West 601, Guangzhou 510632, China \\ ${ }^{2}$ Department of Chemical Engineering, King Saud University, P.O. Box 800, Riyadh 11421, Saudi \\ Arabia \\ ${ }^{3}$ Biopolymers and Thermo physical Laboratories, Department of Chemistry, Sri Venkateswara \\ University, Tirupati - 517502, A.P., India. \\ *E-mail: shivanadavala@gmail.com, snadavala@ksu.edu.sa, masif@ksu.edu.sa
}

doi: $10.20964 / 2016.12 .69$

Received: 24 August 2016 / Accepted: 13 October 2016 / Published: 10 November 2016

In this paper, we report an environmentally friendly, fast and cost-effective method for the synthesis of silver nanoparticles using aqueous Mimosa pudica root extract as reducing and stabilizing agent. Synthesized silver nanoparticles were confirmed by analyzing the excitation of surface plasmon resonance (SPR) using UV-visible spectrophotometer peak at $430 \mathrm{~nm}$. The presence of functional groups in the plant extracts were identified by FTIR analysis. Spherical shaped, crystalline in nature and 35-42.5 $\mathrm{nm}$ sized particles were recorded using TEM and XRD analysis. The surface morphology of the AgNPs was identified by using SEM while the energy-dispersive X-ray spectroscopy (EDAX) confirmed the presence of silver metal ion. The aqueous root extract of $M$. pudica exhibited significant antimicrobial activity against both gram positive (B. subtilis) and gram negative (E. coli, P. aeruginosa) microorganisms. Moreover, Cyclic Voltammetry (CV) results showed a substantial enhancement of peak current using synthesized AgNPs-assembled-glassy carbon electrode (GCE) as compared to bare-GCE. The present AgNPs-assembled-GCE displayed very high sensitivity and excellent linearity to the detection of dopamine (DA) which is a neurotransmitter released by the brain.

Keywords: Biosynthesis; Mimosa pudica root extract; Silver nanoparticles; Antibacterial activity; Dopamine; Cyclic Voltammetry.

\section{$\underline{\text { FULL TEXT }}$}


(C) 2016 The Authors. Published by ESG (www.electrochemsci.org). This article is an open access article distributed under the terms and conditions of the Creative Commons Attribution license (http://creativecommons.org/licenses/by/4.0/). 